\title{
Jacqueline Boucher, Société et mentalités autour de
} Henri III

\section{Filippo Fassina}

\section{Q OpenEdition \\ 1 Journals}

\section{Edizione digitale}

URL: http://journals.openedition.org/studifrancesi/8875

DOI: 10.4000/studifrancesi.8875

ISSN: 2421-5856

\section{Editore}

Rosenberg \& Sellier

\section{Edizione cartacea}

Data di pubblicazione: 1 octobre 2008

Paginazione: 443

ISSN: 0039-2944

\section{Notizia bibliografica digitale}

Filippo Fassina, «Jacqueline Boucher, Société et mentalités autour de Henri IIl», Studi Francesi [Online], 155 (LII | II) | 2008, online dal 30 novembre 2015, consultato il 12 janvier 2021. URL: http:// journals.openedition.org/studifrancesi/8875 ; DOI: https://doi.org/10.4000/studifrancesi.8875

Questo documento è stato generato automaticamente il 12 janvier 2021.

\section{(c) (i) (9)}

Studi Francesi è distribuita con Licenza Creative Commons Attribuzione - Non commerciale - Non opere derivate 4.0 Internazionale. 


\title{
Jacqueline Boucher, Société et mentalités autour de Henri III
}

\author{
Filippo Fassina
}

\section{NOTIZIA}

JACQUELINE BOUCHER, Société et mentalités autour de Henri III, Paris, Champion, 2007

(«Bibliothèque littéraire de la Renaissance», 67), pp. 1273.

Il presente lavoro si configura come uno studio approfondito e completo non solo sulla figura di Enrico III e sulla sua corte, ma anche - e soprattutto - sui legami sociali e intellettuali creatisi nell'entourage del sovrano, una figura molto spesso discussa e controversa. Un capitolo preliminare è dedicato al ritratto fisico e morale del re, che ne evidenzia sia l'aspetto ufficiale, sia quello privato e familiare. Una parte cospicua del lavoro è consacrata all'analisi della corte di Enrico III e ne descrive minuziosamente i componenti e l'organizzazione sociale, senza trascurare gli aspetti più concreti e materiali. Interessante, in questa parte, è lo spazio dato alla presenza di italiani nella corte che, come sottolinea l'A., costituisce un esempio di integrazione complessa e spesso problematica. La seconda sezione è, invece, dedicata alla cultura e alla letteratura, ambiti fortemente sostenuti dal sovrano. L'analisi si sofferma sulle tendenze e sul gusto degli intellettuali, evidenziandone gli aspetti ormai barocchi che consistono nella predilezione per la teatralità e il macabro, e per il continuo emergere del tema dell'incostanza. Prezioso per ricostruire la cultura e i gusti di Enrico III è il catalogo delle opere presenti nella biblioteca personale del sovrano, che dimostrano ricchezza e vivacità di interessi. Infine, un'ultima parte è consacrata a come si configura il cattolicesimo negli ambienti di corte e a come l'entourage del re reagisce nella lotta al protestantesimo. Da notare un'appendice contenente dati economici sulle imposte e sui conti della corte e alcuni documenti, sia di carattere tecnico, sia letterario e sociale e un apparato bibliografico ricchissimo. Il lavoro di J. Boucher è pertanto un 
utile strumento per ricostruire la vita sociale e culturale della corte francese nel periodo post-rinascimentale. 